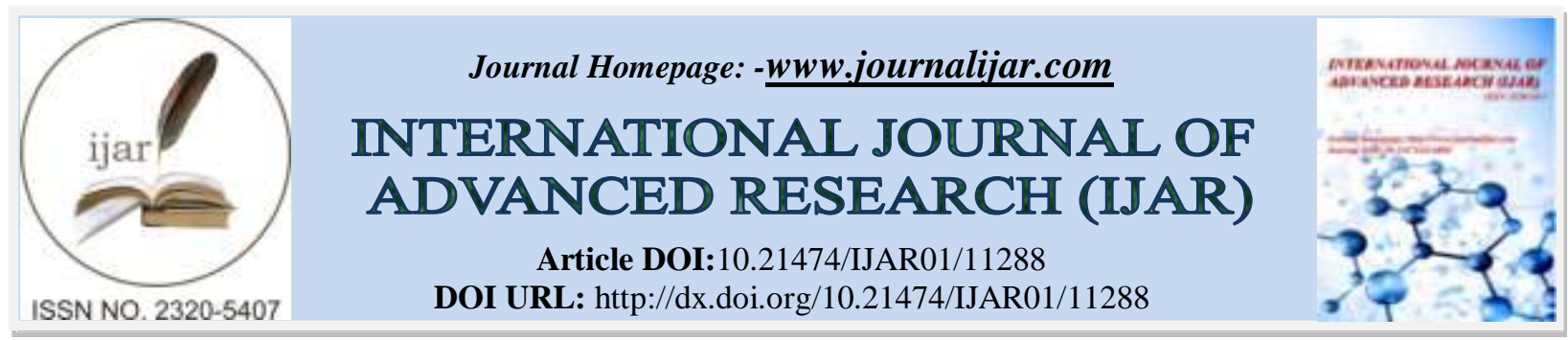

RESEARCH ARTICLE

\title{
EFFECT OF NANO HYDROXYAPATITE ON NORMAL AND GAMMA IRRADIATED HUMAN ENAMEL SURFACE AFTER ORTHODONTIC TREATMENT (SEM STUDY)
}

\section{Fatma Abdelaziz ${ }^{1}$, Shimaa M Ameen ${ }^{2}$ and Dalia El-Rouby ${ }^{3}$}

1. Professor of Orthodontics, Faculty of Dental Medicine, Al-Azhar University, Girls Branch, Prof \& Head of Orthodontic Depart. Nahda University Egypt.

2. Lecturer of Operative Dentistry, Faculty of Dental Medicine, Al-Azhar University, Girls' Branch, Cairo, Egypt.

3. Professor, Oral Pathology, Faculty of Dentistry, Cairo University.

\section{Manuscript Info}

Manuscript History

Received: 05 May 2020

Final Accepted: 10 June 2020

Published: July 2020

Key words:-

Enamel Surface, Scanning Electron

Microscopy, Nano-Hydroxyapatite,

Remineralization

\section{Abstract}

Objectives: To evaluate the effect of Nano-Hydroxyapatite gel on the remineralization of normal and gamma irradiated human enamel surface before orthodontic bracket bonding and after brackets debonding, using scanning electron microscope. Methods: A total number of sixty extracted sound human premolars teeth were collected. The sample was divided into two equal groups according to exposure to radiation: Group 1: Irradiated Enamel, Group 2: Non-Irradiated Enamel. Each group was further divided into three subgroups; subgroup i, application of Nano-hydroxyapatite before bonding of orthodontic brackets, subgroup ii, application of Nano-hydroxyapatite after debonding of orthodontic brackets and subgroup iii: no application (control group). Results: SEM of normal enamel surface revealed masking of the prismatic structure by a layer of partially adsorbed Nanohydroxyapatite crystals. Hydroxyapatite crystals microclusters of variables sizes adhered to the enamel surface. Irradiated enamel revealed a spattered deposit showing focal micro pits denoting the adherence of nanocrystals to the pores created by radiation. Nanohydroxyapatite application after orthodontic bracket debonding of normal Enamel showed areas with maintained prismatic structure alternating with areas showing damaged enamel micro-surface. Higher magnifications revealed confluence of the prismatic and inter-prismatic structures and surface irregularities.

Conclusions: Nano-hydroxyapatite helped maintenance of the prismatic structure after orthodontic brackets debonding. Partially repaired enamel surface and microstructural alterations were observed in irradiated Nano-hydroxyapatite treated teeth. Application of Nanohydroxyapatite before bonding of orthodontic brackets helps preservation of enamel structure.

Copy Right, IJAR, 2020,. All rights reserved.

Corresponding Author:- Shimaa Mahmoud Ameen

Address:- Lecturer of Operative Dentistry, Faculty of Dental Medicine, Al Azhar University, Girls' Branch, Cairo, Egypt. 


\section{Introduction:-}

The remarkable risk associated with orthodontic treatment is the enamel demineralization when oral hygiene is poor. Inhibition of demineralization during orthodontic treatment is the major challenge faced by orthodontist despite the recent development in caries prevention protocols. The progression of white spot lesions (WSLs) is related to elongated plaque collection around the brackets(Gorelick L et al., 1982).

The last step within the fixed orthodontic treatment isthe removal of bonded brackets and restoring the enamel surface as closely as possible to the first pretreatment state. Bonding and debonding procedures can cause irreversible changes on the enamel surface, which are more important when they occur on the most resistant outer layer(Ajami S et al., 2016), (Özer T et al., 2010). These potential alterations involve up to $55 \mu \mathrm{m}$ enamel loss(Arhun $\mathrm{N}$ and Arman A 2007) increased surface roughness and therefore, more susceptibility to demineralization and discoloration(Quirynen M and Bollen CM 1995)

Radiation therapy is a treatment modality that uses ionizing radiation as a therapeutic agent(Chaachouay $\mathrm{H}$ 2011).It is widely employed for the treatment of head and neck cancer, as an adjuvant primary therapy to surgical treatment in conjunction with chemotherapy or as a palliative treatment for advanced or inoperable tumors(Soares CJ et al., 2011). The most common manifestations or complications of radiation therapy in the head and neck region are xerostomia, mucositis, candidiasis, dysgeusia, loss of taste, muscular trismus, vascular alterations, osteoradionecrosis and radiation caries. Radiation caries is a complex and destructive multifactorial disease that affects patients undergoing radiation therapy in the head and neck region(Silva AR et al,.2009),(Goncalves L et al,.2014). This is the most complication of radiotherapy in this region.

One of the foremost effective remineralizing agents in caries prevention is fluoride. Nevertheless, some concerns have been expressed about fluorosis and total fluoride intake(Li X. et al, .2014), (Malekafzali Bet al, .2015). In recent years, fluoride alternatives have been proposed, including CPP-ACP and nano-hydroxyapatite (NHA) because of their anti-cariogenic characteristics (Kalra DD et al,. 2014),(Vyavhare S et al,. 2015). HA contains calcium and phosphate crystals that are found in cementum, enamel and dentin. Because of similar characteristics to human hard tissue, biocompatibility and low solubility in humid environments, HA has received great attention in medicine, dentistry and biology. Anti-bacterial effect of HA is one of the most important properties that has been shown in several studies(Zhang L et al, .2000). Many studies have used HA for enamel lesion repair due to its chemical and structural similarity to tooth mineral content (Haghgoo R et al, .2012).Biomimetic effect of the nanohydroxyapatite is based onits interaction with biological tissues and on its ability tomimic biogenic materials in their functionalities. Chemicalcomposition is similar to enamel and dentin, with intermediate characteristics.(ScribanteA et al,.2020)

Remineralization of enamel with $10 \%$ NHA led to a reduction in depth of damage regardlessof the type of adhesive removal technique used. A postulated rationale for this is that the NHAtreatment was able to increase the mineral content of demineralized enamel and became able towithstand the damaging forces applied during adhesive removal (Cochrane NJ et al, .2012).

Recently NHA has been combined with a source of fluoride in both tooth pastes and an oral rinse. In such products it is possible that the fluoride may combine with the phosphate and calcium ions released from the apatite of enamel during an acid challenge and could reform as fluorapatite(Mohammed NR et al, .2013) As already noted, enamel surface damage is an inevitable sequela of the orthodontic debonding procedure,in addition to the deleterious effect of radiotherapy on the enamel surface. Therefore, the aim of this in vitro study was to evaluate the effect of NanoHydroxyapatite gel on the remineralization of normal and gamma-irradiated human enamel surface before orthodontic bracket bonding and after debonding of brackets through scanning electron microscopy (SEM).

\section{Methods:-}

\section{Grouping of samples:}

A total number of 60 sound human premolars teeth extracted as planned for orthodontic treatment were collected. The selection criteria were sound teeth with no hypoplastic or carious lesions, absence of apparent cracks and restorations. The samples were cleaned and stored in distilled water at room temperature. The distilled water was changed weekly to prevent bacterial growth. 
The sample was assigned into two groups of equal number according to exposure to radiation: Group 1:Irradiated Enamel, Group 2:Non-Irradiated Enamel. Each group was further divided into three subgroups:

1. application of NHA before bonding of orthodontic brackets,

2. application of NHA after debonding of orthodontic brackets

3. no NHA application (control group).

\section{Irradiation, bonding and debonding of brackets}

The teeth have been irradiated by Elekta linear acceleration. The dose given was single dose 17.27 Gy of $6 \mathrm{MV}$ energy equivalent to $70 \mathrm{~Gy} / 35$ fractions using alpha beta ratio 3 (normal tissue). The teeth have been preserved in distilled water for a period of 8 weeks to allow maximum effect of radiation.

Stainless steel Roth prescription metal brackets were bonded to the buccal surface of the extracted premolars with 3M Unitek's Unite ${ }^{\mathrm{TM}}$ light cured Bonding Adhesiveorthodontic composite. Samples were stored in distilled water at room temperature for $24 \mathrm{~h}$ to ensure complete resin polymerization, thenmounted into acrylic blocks through metal rings.

Brackets were peeled off with a hand plier by gently squeezing the mesial and distal wings together. Remnant resin was removed with 12-fluted tungsten carbide bur, operated in low-speed and air cooling, and finally polished with a rubber cup and slurry of fine pumice for 10 seconds. Complete removal of residual resin was confirmed by visual inspection under the light of a dental operating lamp.

The application of Nano-hydroxyapatite (NHA) gel:

Calmodent professional InterMed S.A. Greece, containing 20\% nano-hydroxyapatite and 2000ppm stannous fluoride was applied to the teeth with small brush, as specified for each subgroup

Scanning electron microscopic examination was performed in order to compare morphological changes of enamel surface after irradiation and the effect of application of NHA. Scanning was performed by Quanta Feg250 Scanning Electron Microscope Unit. Teeth were air-dried then fixed to the stubs with a double-sided adhesive carbon tape with their buccal surface up in order to examine the enamel buccal surface.

\section{Results:-}

\section{Normal and irradiated Enamel surface:}

By using magnification (X500), in normal enamel (group II-iii), enamel prism endings and circumferentially horizontal lines representing perikymatawere evident on all over the surface (Fig.1), while irradiated Enamel (group I-iii), showed faint perikymatic grooves and ridges, with very few prismatic endings all over the enamel surface. (Fig.2)

By using magnification (X1000), Normal enamel (group II-iii), displayed well organized numerous small pits which represent the prism ending surrounded by smooth elevated interprismatic regions (Fig.1), while Irradiated Enamel (group I-iii) showed alterations of enamel surface representing widening of enamel prism ending especially in the grooves impairing the identification of prisms. (Fig.2)

By using (X2000 mag.),Normal Enamel(group II-iii), showed clearer image for prism ending and inter prismatic areas with few micro cracks (Fig.1), while irradiated Enamel(group II-iii), showed marked pores all over the prismatic and interprismatic areas of enamel, precluding the visualization of prisms. Crystalline structural detachment was observed surrounded by structural degeneration (Fig.2). Atmagnification (X 4000) enamel structure appeared ruined after radiation, showing fish scale appearance in conjunction with massive prism core disintegration. The enamel surface had an irregular rough granular appearance with marked pitting and furrows (Fig.2).

\section{Application of NHA gel:}

\section{NHA gel application before orthodontic bracket bonding:}

By using magnification, (X500), normal Enamel (group II-i)showed masking of the prismatic structure by a layer of partially adsorbed nanohydroxyapatite crystals. By using magnification, (X1000), the surface of the enamel appeared irregular with flakes of deposits and HA crystals microclusters of variables sizes. Using higher magnifications, (X2000 and X4000), the keyhole appearance of the enamel prism was concealed by a rough-surfaced layer of varying 
thicknessand with spattered deposits showing focal micro pits denoting the adherence of HA nanocrystals to the pores created by radiation (Fig.3)

At low magnification (X500),Irradiated Enamel (group I-i) showedextensive fissuring of the enamel surface. Examination using (x1000) magnification revealed surface alterations with widespread and intense cracks and micro-porosities. Higher magnifications, (X2000 and X4000), illustrated areas showing confluence of prismatic and inter-prismatic structures alternating with areas showing several local micropits and irregular fissures (Fig. 4)

\section{NHA after orthodontic bracket debonding:}

By using magnification, (X500), normal Enamel (group II-ii) showed areas with maintained prismatic structure alternating with areas showing damaged enamel micro-surface. By using magnification, (X1000), the surface of the enamel appeared irregular with flakes of deposits and focal pitted areas. Examination using (X1000 org. mag.), revealed masking of the prismatic structure by the partially adsorbed nanohydroxyapatite giving an irregular rough appearance. Higher magnifications, (X2000 and X4000), revealed confluence of the prismatic and inter-prismatic structures and surface irregularities (Fig.5)

At low magnifications (X500, X1000),Irradiated Enamel (group I-ii) periprismatic clefts and microdeposits were observed. Enamel revealed maintenance of prismatic structure and tightly packed mass of enamel prisms. At higher magnification (X2000, X4000), the prism boundaries appeared indistinct in focal areas. Prisms were separated by various amount of interprismatic substance. Their configurations appeared either as round, fish scale like, keyhole or polygonal.Cracks and furrows were demonstrated giving an irregular surface appearance (Fig. 6)

\section{Discussion:-}

Scanning electron microscopy (SEM) is a useful and powerful tool to evaluate the effect of gamma irradiation on hard dental tissues helping to predict where failure initiate and which structures are more or less influenced by radiotherapy(Soares CJ et al,.2010a). SEM was used in that study to evaluate enamel surface which is the outer surface subjected to radiation. Comparison was done between normal and irradiated enamel, before orthodontic bracket bonding and after orthodontic bracket debonding, all samples were evaluated at the same magnification powers. The study was started with low power magnifications and since there were nearly the same morphological features for normal and irradiated enamel such as parallel wavy appearance of the perikymatic ridges so higher power magnifications were incorporated.

In the present study, non-irradiated enamel showed well organized prism crystalline structure with no cracks or damages and well defined prismatic and interprismatic regions. However, change in organization was observed after radiation treatment which was obvious at higher magnification, showing drastic change in the prismatic alignment of the crystalline structures, fish scale appearance, and structural detachment. These results were in agreement with studies which stated that SEM of irradiated enamel showed interprismatic space, marked loss of defined structures and depicted amorphous substances or melted appearance(Hegde M et al,.2015),(Soares CJ et al,.2010b).

In irradiated enamel, areasshowing crystal detachment denote that the enamel structure below it is very weak. This may result from the effect of radiotherapy in increasing the stiffness and decreasing the protein content near dentinoenamel junction (DEJ). Such changes in mechanical properties and chemical composition could potentially contribute to DEJ biomechanical failure leading to enamel delamination post-radiotherapyin addition to protein degradation with subsequent tooth fragility. (Epstein JB et al,.1996),(Reed R et al,.2015).

The present study clearly signifies that irradiation has a damaging effect on the morphological properties of the enamel surface as seen by SEM. Preventive measures, before, during and after radiotherapy are therefore necessary and should include instructions regarding a non-cariogenic diet, thorough regular oral hygiene and application of topical fluoridein order to reduce the incidence of post-radiation caries in enamel and dentin.

The surface layer of enamel is characterized by high content of minerals and fluoride which protects the underlying enamel from organic acids produced in dental microbial plaque. (Øgaard 2001) B Moreover, increased enamel surface roughness after debonding results in increased accumulation of pigments, retention of bacterial plaque with subsequent decalcification, ultimately causing esthetic problems.(Berger SB et al., 2011),(Roveri N et al,.2009). Nanostructured hydroxyl Apatite crystals exhibit high levels of biomimetic properties due to their composition, morphology, bulk and surface physical and chemical properties.(Li L et al,.2008).In this NHA gel was applied on 
normal and irradiated enamel before orthodontic bracket bonding and after orthodontic bracket debonding in order to improve the enamel surface morphology after orthodontic treatment. The SEM study of the enamel surface after application of NHA gel revealed that HA particles adhered to the enamel surface pores created by demineralization and irradiation. Moreover, the enamel surface showed a newly formed apatite layer that covered the prismatic and interprismatic enamel structures. These findings were in accordance with previous SEM studies which stated that the adherence of HA nanocrystals to the pores created by demineralization induced remineralization of the enamel surface. These adherent nanocrystals were found to aggregate and grow into microclusters and form a uniform apatite layer on the demineralized surface.(Swarup S and Rao A 2012). With its chemical and structural similarity to the enamel inorganic structure, NHAP is superior to the conventional synthetic HAP in repairing damaged enamel. (Li L et al,.2008). This can be explained by the characteristic high surface energy and strong affinity of nanoscale HAP to the enamel surface.(Lin K et al,.2014)

Scanning electron microscopic evaluation of normal enamel with NHA after orthodontic bracket debonding revealed an irregular enamel surfacewith flakes of deposits. The prismatic structure was masked by partially adsorbed nanohydroxyapatite giving an irregular rough appearance. This could explained by the fact that, although the completion of resin removal was verified with visual inspection; however, remnants could still be present, thus hindering the adsorption of nanoHAP particles and resulting in irregular rough enamel appearance.

In the present study, irradiated enamel with NHA before orthodontic bracket bonding showed surface alterations manifested as extensive fissuring of the enamel surface, widespread and intense cracks, micro-porosities and local micropits. (Jansma et al,.1988) suggested that radiation does not present direct effects on the inorganic structure of human teeth, and that the observed dental alterations in patients with head and neck cancer after radiation therapy are due instead to the alterations in the organic matrix of enamel. (Gonçalves et al,.2014). SEM study confirmed this by revealing more significant morphological alterations in the interprismatic region, which corresponds to enamel organic matrix and suggested that the alterations in the interprismatic region, which concentrates water, result from free radicals and reactive oxygen species accumulation that may react with and damage organic components. These previous studies thus pointed to the fact that ionizing radiation influence the interprismatic structure rather than the rod structure. It has been suggested thatnanohydroxyapatite HAP is analogous to the subunits of biological apatite and can repair enamel surfaces by surface adsorption of numerous nanoparticles, which tend to array along the natural rod structures. (Li L et al,.2008).However, this repair mechanism is of little benefit in case of ionizing radiation since the defect is located in the organic matrix; thus explaining why surface alterations are still present in irradiated enamel in the current study even after NHA application.

In considering adhesive removal, two aspects of iatrogenic enamel damage should be considered: enamel loss by etching, grinding, and subsequent polishing; and increasing enamel roughness by scratching or faceting. Moreover, removal of external enamel layer leads to increased susceptibility to demineralization due to exposing enamel prisms endings, since the most external enamel layer is harder and more mineralized than the deeper zones and should be protected (Janiszewska-Olszowska J et al,.2014).

In the present work, irradiated enamel after orthodontic bracket debonding showed periprismatic clefts and microdeposits. Although enamel revealed preservation of prismatic structure and tightly packed mass of enamel prisms; however, cracks and furrows were observed giving an irregular surface appearance. These findings denotes the beneficial role of NHA in preservation of the prismatic structure to a certain extent. However, the damaging effect of ionizing radiation and brackets debonding could not be totally reversed.

\section{Conclusion:-}

Nanohydroxyapatite HAP partially repaired enamel surface by surface adsorption and helped maintenance of the prismatic structure after orthodontic brackets debonding. However, microstructural alterations were still observed in irradiated NHA-treated teeth emphasizing that the effect of ionizing radiation resides in the organic matrix, and therefore couldn't be totally reversed by NHA application 


\section{Illustration Legends:}

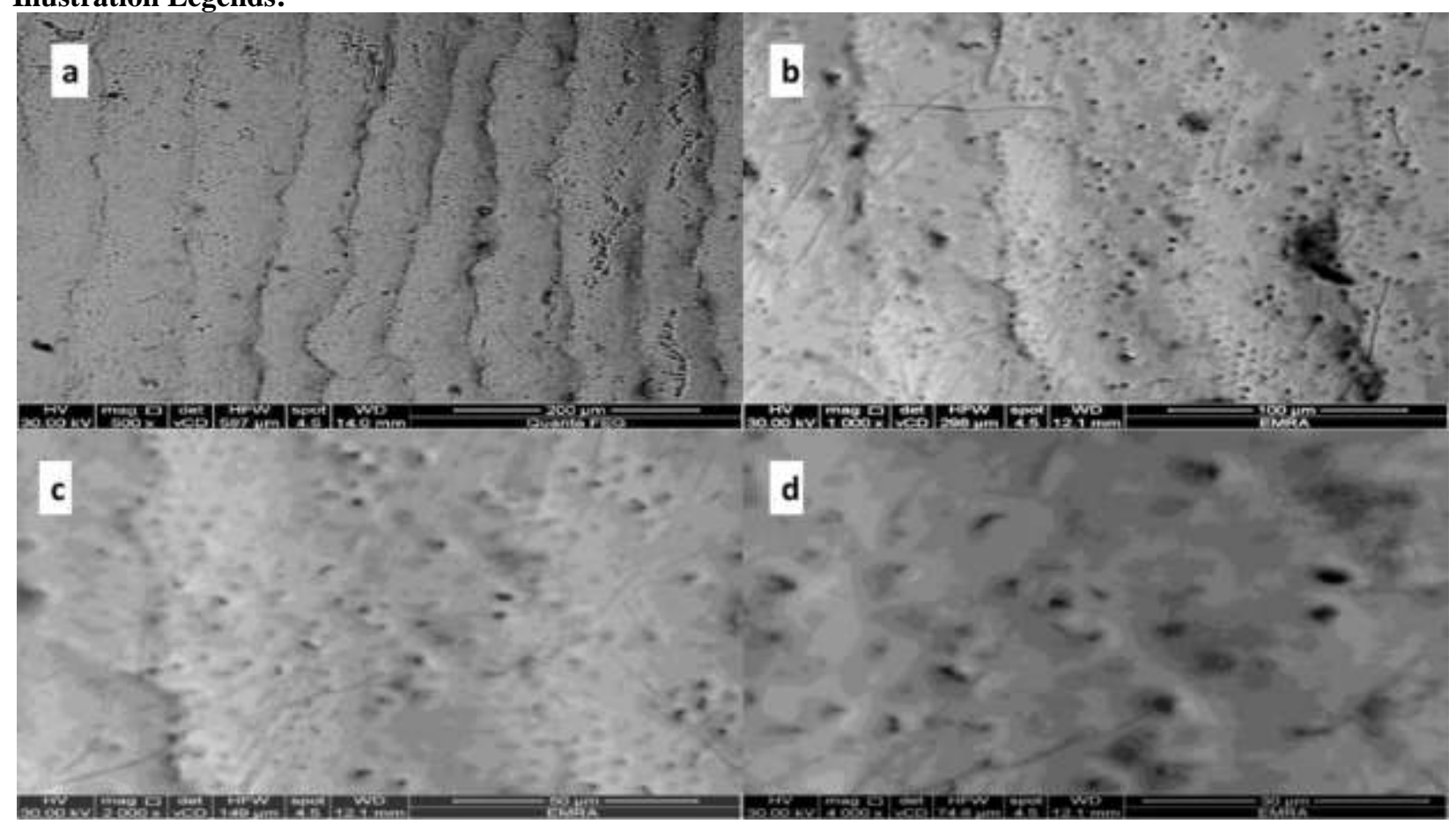

Fig. 1:- Normal Enamel (Group II, iii), SEM micrograph showing normal enamel prism ends and interprismatic structure. [Org. mag.X500 (a), 1000 (b), 2000 (c) \&4000 (d)].

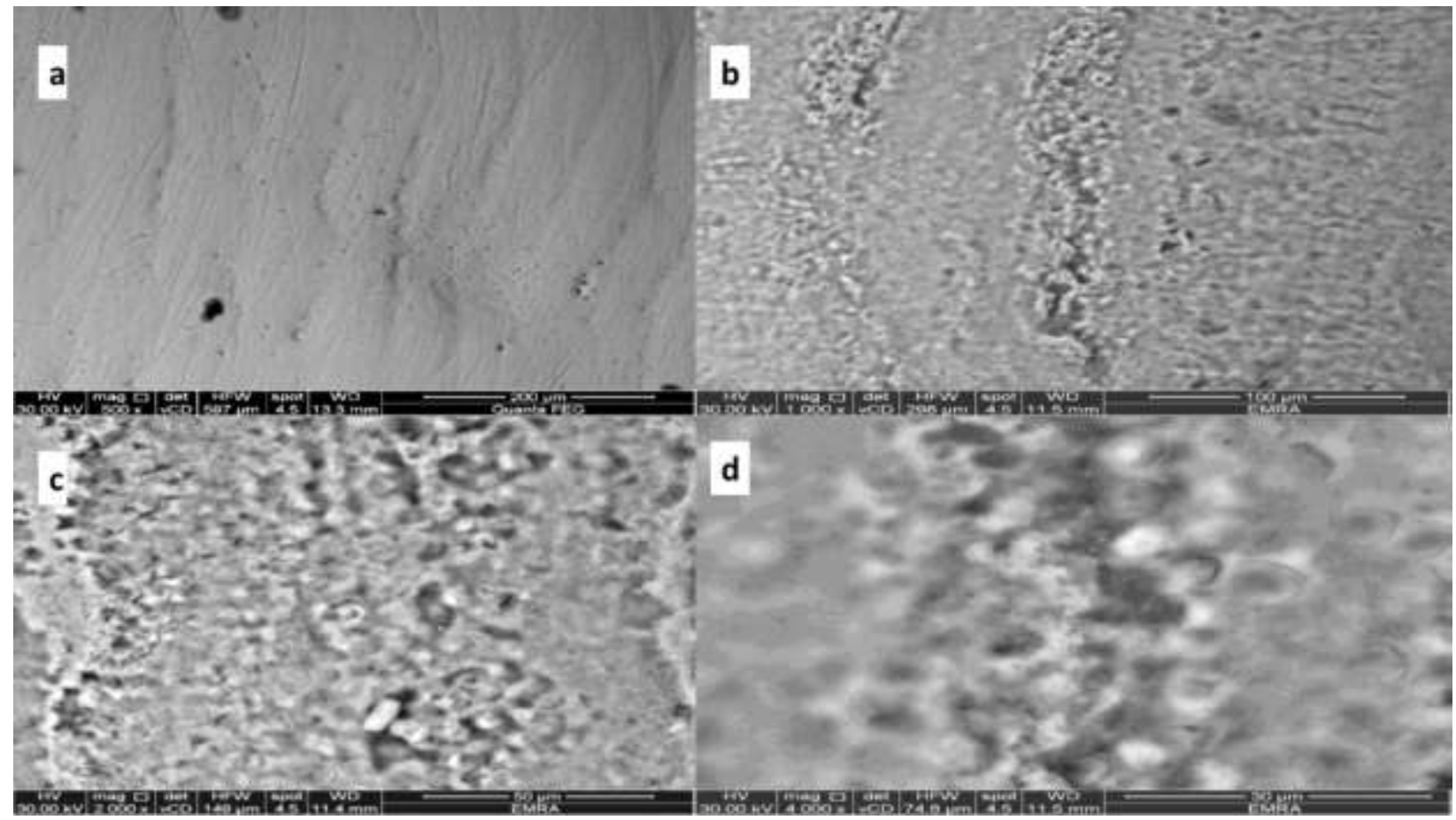

Fig. 2:- Irradiated Enamel (Group I, iii), SEM micrograph showing (a) faint perikymatic grooves and ridges, (b) widening of enamel prism endings impairing the identification of prisms, (c) crystalline structural detachment and structural degeneration, (d) fish scale appearance, massive prism core disintegration and marked pitting and furrows [Org. mag.X500 (a), 1000 (b), 2000 (c) \&4000 (d)]. 


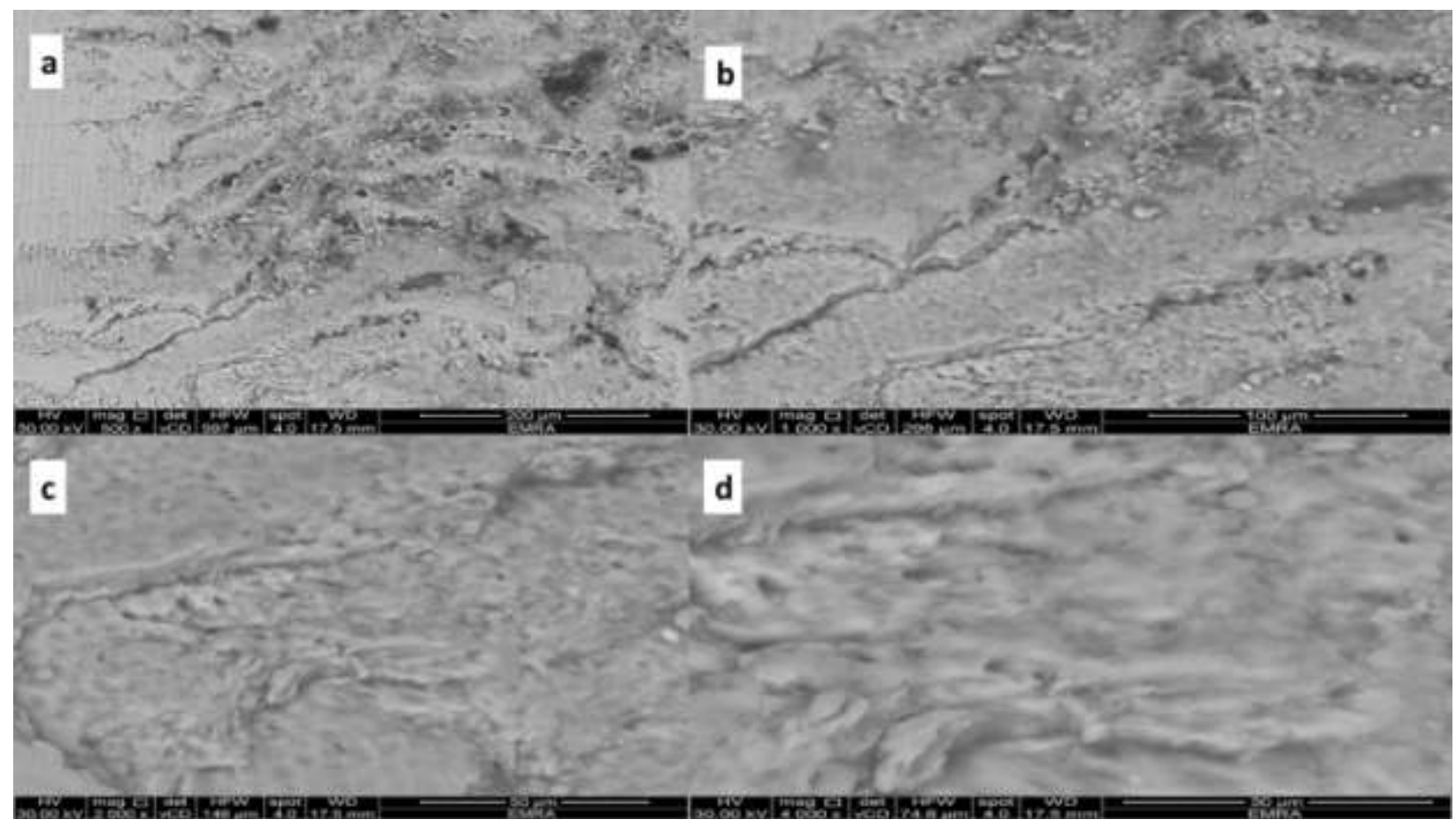

Fig. 3:- Normal enamel with NHA before orthodontic bracket bonding (group II-i), SEM micrograph showing (a) masking of the prismatic structure by a layer of partially adsorbed nanohydroxyapatite crystals, (b) irregular surface with flakes of deposits and microclusters of variables sizes. (c), the enamel prism concealed by a rough-surfaced layer of varying thickness, (d) spattered deposits showing focal micro pits denoting the adherence of HA nanocrystals to the pores created by radiation [Org. mag.X500 (a), 1000 (b), 2000 (c) \&4000 (d)].

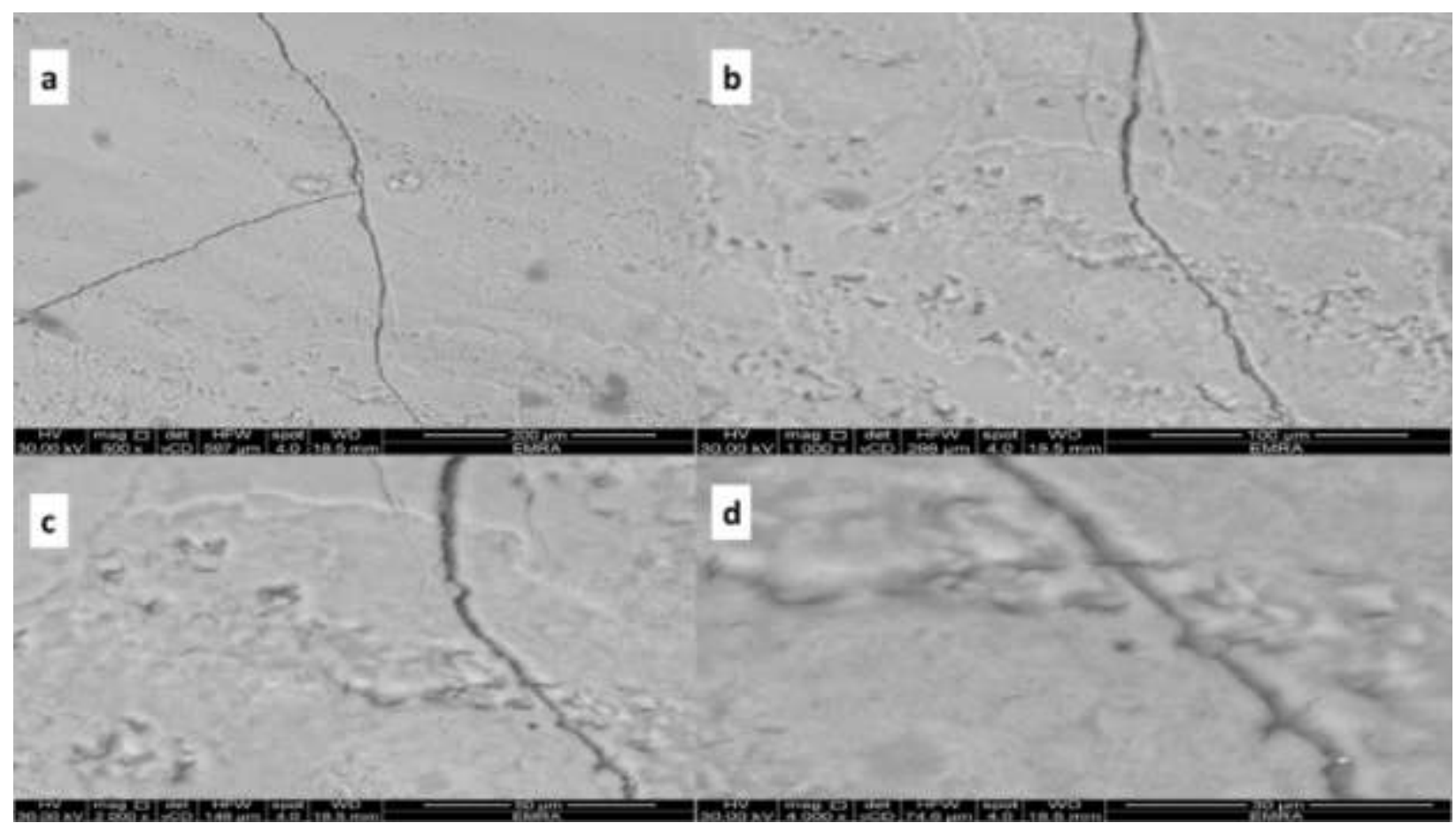

Fig. 4:- Irradiated enamel with NHA before orthodontic bracket bonding (group I-i), SEM micrograph showing (a)showedextensive fissuring of the enamel surface, (b) surface alterations with widespread and intense cracks and micro-porosities, (c\&d) confluence of prismatic and inter-prismatic structures alternating with areas showing several local micropits and irregular fissures [Org. mag.X500 (a), 1000 (b), 2000 (c) \&4000 (d)]. 


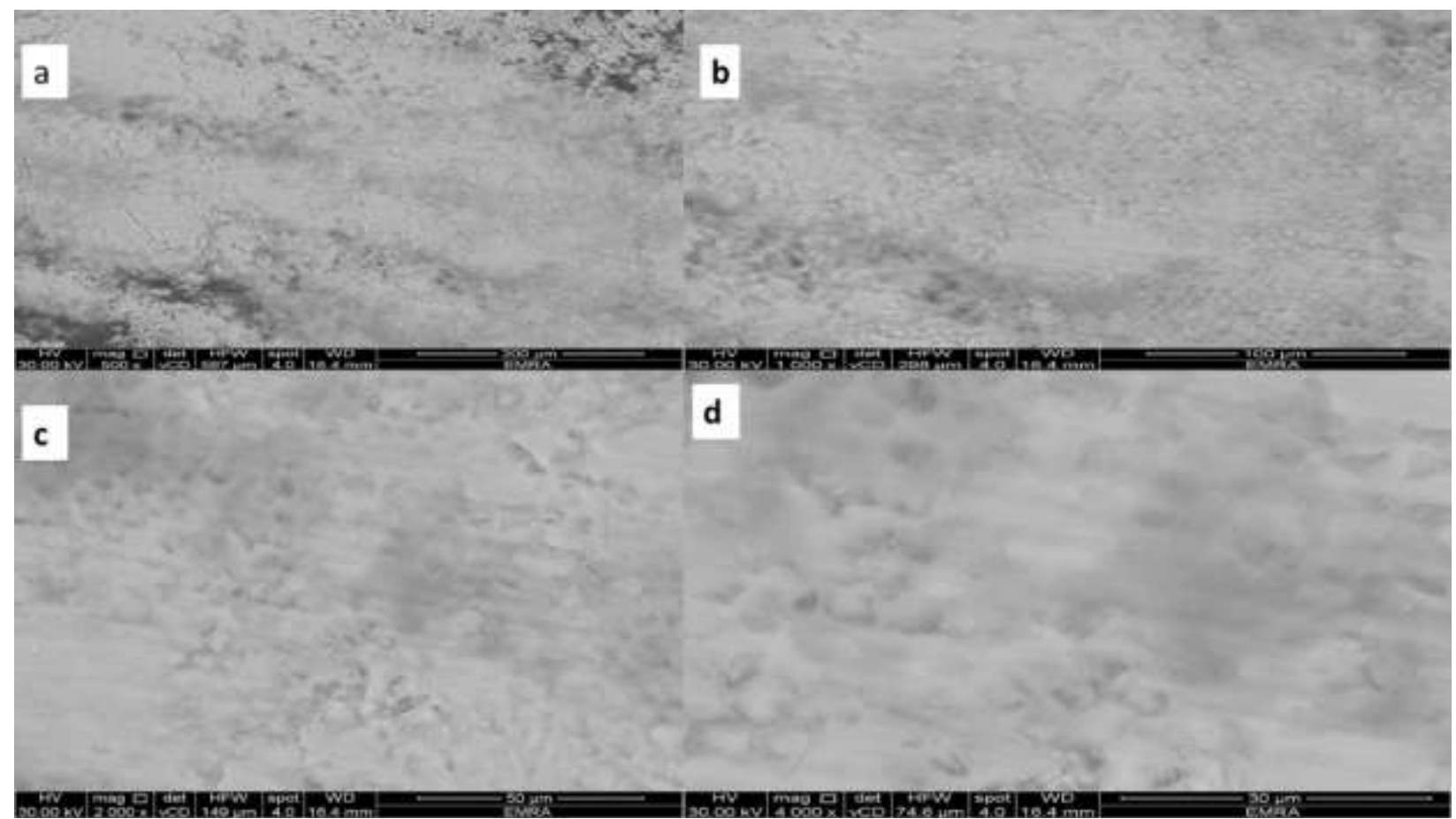

Fig. 5:- Normal enamel with NHA after orthodontic bracket debonding(group II-ii), SEM micrograph showing (a) areas with maintained prismatic structure alternating with areas showing damaged enamel micro-surface, (b) irregular surface with flakes of deposits and focal pitted areas., (c) masking of the prismatic structure by partially adsorbed nanohydroxyapatite, (d) confluence of the prismatic and inter-prismatic structures and surface irregularities [Org. mag.X500 (a), 1000 (b), 2000 (c) \&4000 (d)].

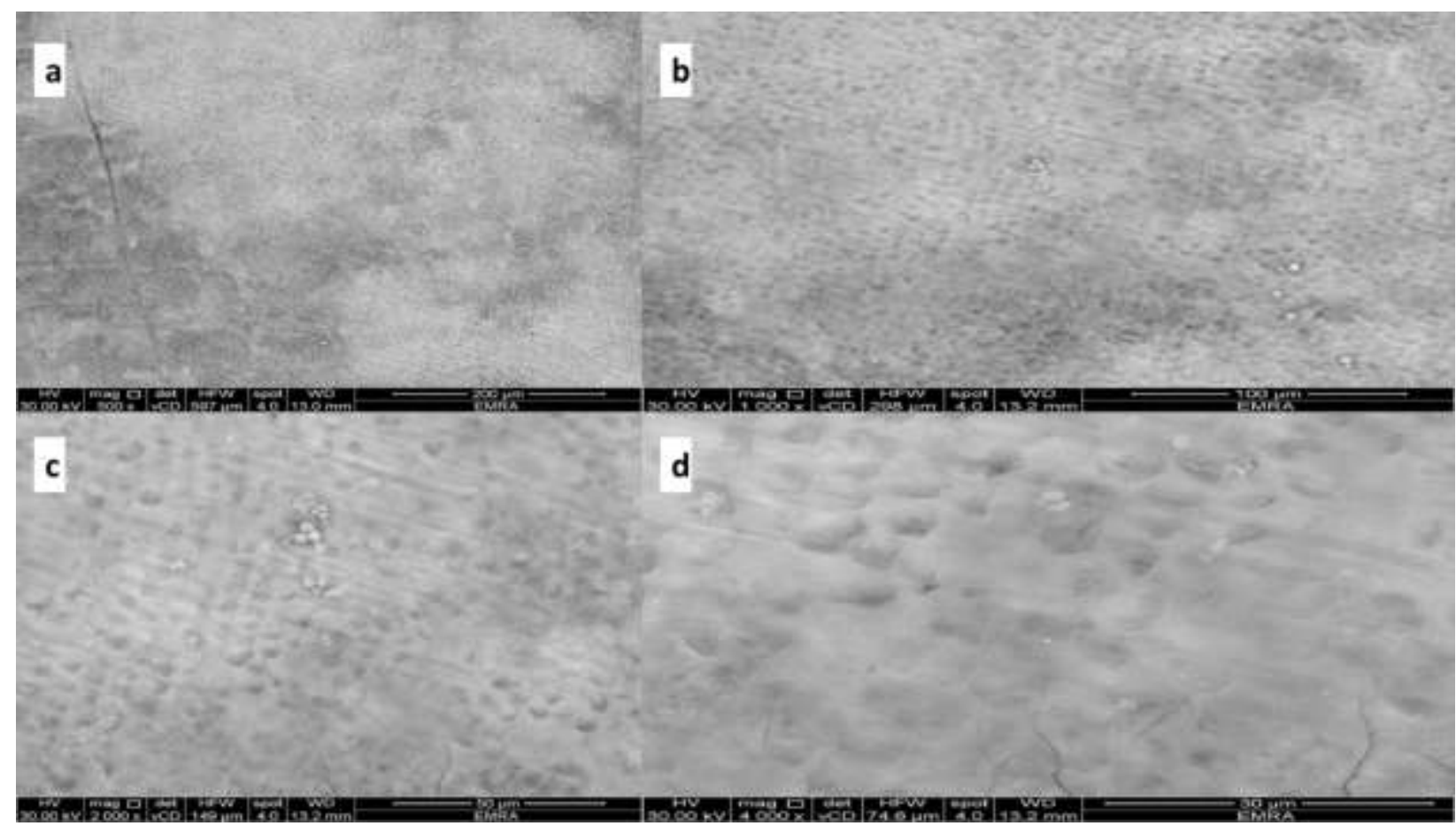

Fig. 6:- Irradiated enamel after orthodontic bracket debonding(group I-ii) ), SEM micrograph showing (a) periprismatic clefts and microdeposits with maintenance of prismatic structure, (b) tightly packed mass of enamel prisms, (c) indistinct prism boundaries separated by various amount of interprismatic substance, (d) Prism configurations as round, fish scale like, keyhole or polygonal [Org. mag.X500 (a), 1000 (b), 2000 (c) \&4000 (d)]. 


\section{References:-}

1. Ajami S, Pakshir H, Babanouri N. Impact of nanohydroxyapatite on enamelsurface roughness and color change after orthodontic debonding.Progress in orthodontics 2016; 17:11-18

2. Arhun N, Arman A. Effects of orthodontic mechanics on tooth enamel: a review. SeminOrthod. 2007; 13:28191.

3. Berger SB, Palialol ARM, Cavalli V, Giannini M. Surface roughness and staining susceptibility of composite resins after finishing and polishing. J EsthetRestor Dent. 2011; 23:34-43.

4. Chaachouay H, Ohneseit P, Toulany M, Kehlbach R, Multhoff G, Rodemann HP. Autophagy contributes to resistance of tumor cells to ionizing radiation. Radiother. andOncol. 2011; 99:287-92.

5. Cochrane NJ, Ratneser S, Reynolds EC. Effect of different orthodontic adhesive removal techniques on sound, demineralized and remineralized enamel. Aust. Dent. J 2012; 57: 365-372.

6. Epstein JB, van der Meij EH, Lunn R, Le ND, Stevenson-Moore P. Effects of compliance with fluoride gel application on caries and caries risk in patients after radiation therapy for head and neck cancer. Oral Surgery, Oral Medicine, Oral Pathology, Oral Radiology, and Endodontology. 1996; 82:268-75.

7. Gonçalves LMN, Palma-Dibb R G, Paula-Silva FWG, de Oliveira HF, Nelson-Filho P, da Silva LA, de Queiroz AM. Radiation therapy alters microhardness and microstructure of enamel and dentin of permanent human teeth. J. Dent. 2014; 42:986 - 992

8. Gorelick L, Geiger AM, Gwinnett AJ. Incidence of white spot formation after bonding and banding. Am J Orthod 1982; 81(2):93-8.

9. Haghgoo R, Ataie M, Tavassoli S, Kameli S, Rahimian S. The effect of various amounts of nanohydroxyapatite on the mechanical properties and remineralization of a fissure sea-lant. J Dent (Tehran). 2012; 30(3):184-91.

10. Hegde M, Hedge N, Kumari S, Sanjeev G, Priya, Radiation effect on structure and mechanical properties of teeth . Eur J Pharm Med Res, 2015; 2:788-800.

11. Janiszewska-Olszowska J, Szatkiewicz T, Tomkowski R., Tandecka K and Grocholewicz K. Effect of Orthodontic Debonding and Adhesive Removal on the Enamel - Current Knowledge and Future Perspectives a Systematic Review. Med SciMonit, 2014; 20: 1991-2001

12. .Jansma J, Buskes JA, Vissink A, Mehta DM, Gravenmade EJ. The effect of X-ray irradiation on the demineralization of bovine dental enamel. A constant composition study. Caries Research 1988; 22:199-203.

13. Kalra DD, Kalra RD, Kini PV, Prabhu CA. Nonfluoride remineralization: An evidence-based review of contemporary technologies. J Dent. \& Allied Sci. 2014; 3(1):24.

14. 24. Li L, Pan H, Tao J, Xu X, Mao C, Gu X and Tang R. Repair of enamel by using hydroxyapatite nanoparticles as the building blocks. J Mater Chem 2008; 18:4079-84.

15. Lin K, Wu C, Chang J. Advances in synthesis of calcium phosphate crystals with controlled size and shape. ActaBiomater. 2014;10:4071-102

16. Li X, Wang J, Joiner A, Chang J. The remineralisation of enamel: a review of the literature. J Dent. 2014; 42Suppl 1:S12-20.

17. Malekafzali B, Ekrami M, Mirfasihi A, Abdolazimi Z. Remineralizing Effect of Child Formula Dentifrices on Artificial Enamel Caries Using a pH Cycling Model. J Dent (Tehran). 2015; 12(1):11-7.

18. Mohammed NR, Kent NW,LynchR JM, Karpukhina N, HillR, Anderson P. Effects of fluoride on in vitro enamel demineralization analyzed by 19 FMAS- NMR. Caries Res 2013; 47:421-28.

19. Özer T, Başaran G, Kama JD. Surface roughness of the restored enamel after orthodontic treatment. Am J OrthodDentofacOrthop. 2010;137:368-74

20. Qugaard B. Oral microbiological changes, long-term enamel alterations due to decalcification, and caries prophylactic aspects, in: Orthod. Mater. Sci. Clin. Asp., Stuttgart, Germany: Thieme; 2001; $123-142$.

21. Quirynen M, Bollen CM. The influence of surface roughness and surface-free energy on supra- and subgingival plaque formation in man. A review of the literature. J ClinPeriodontol. 1995; 22:1-14.

22. Reed R, Xu C, Liu Y, Gorski JP, Wang Y, Walker MP. Radiotherapy effect on nano-mechanical properties and chemical composition of enamel and dentine. Archives of oral biology. 2015; 5:690-97.

23. Roveri N, Battisella E, Bianchi CL, Foltran I, Foresti E and Iafisco M et al. Surface enamel remineralization: Biomemetic apatite nanocrystals and fluoride ions different effects. J Nanomater 2009; vol 2009:1-9.

24. Scribante A, Farahani M, Marino G, Matera C, Baena R, Lanteri V, Butera A. Biomimetic Effect of NanoHydroxyapatite in Demineralized Enamel before Orthodontic Bonding of Brackets and Attachments: Visual, Adhesion Strength, andHardness in In Vitro Tests. BioMed Res.int.2020;2020:1-9

25. Silva AR, Alves FA, Antunes A, Goes MF, Lopes MA. Patterns of demineralization and dentin reactions in radiation related caries. Caries Res. 2009;43:43-9. 
26. Soares CJ, Castro CG, Neiva NA, Soares PV, Santos-Filho PC, Naves LZ, Pereira PN. Effect of gamma irradiation on ultimate tensile strength of enamel and dentin. J. Dent. Res. 2010; 89:659-64.

27. Soares CJ, Moura CC, Soares PB, Naves LZ. Scanning electric microscopy used to analyze the effect of gamma irradiation on enamel and dentin. Microscopy: science, technology, application and education. A Mendez-Vilas and J Diaz. 2010:372-78.

28. Soares CJ, Neiva NA, Soares PB, Dechichi P, Novais VR, Naves LZ, et al. Effects of chlorhexidine and fluoride on irradiated enamel and dentin. J. Dent. Res. 2011; 90:659-64.

29. Swarup S. and Rao A. Enamel surface remineralization: using synthetic nanohydroxyapatite. Contemporary clinical dentistry, Oct-Dec; 2012:433-36.

30. Vyavhare S, Sharma DS, Kulkarni VK. Effect of three different pastes on remineralization of initial enamel lesion: an in vitro study. J ClinPediatr Dent. 2015; 39(2):149-60.

31. Zhang L, Li Z, Dong Y. Experimental study of phosphopeptide in promoting tooth remineralization. Chinese J. Dent. Res. 2000; 3(1):27-30. 